Volume 3

Issue 4 -- Cardiovascular Aging

Article 1

$11-11-2016$

\title{
Seniors Welcome! Avoiding the Trap of Age Limits in Health Research
}

Arshad Jahangir

Follow this and additional works at: https://aah.org/jpcrr

Part of the Biological Phenomena, Cell Phenomena, and Immunity Commons, Cardiology Commons, Cardiovascular Diseases Commons, Circulatory and Respiratory Physiology Commons, Physiological Processes Commons, Therapeutics Commons, and the Translational Medical Research Commons

\section{Recommended Citation}

Jahangir A. Seniors welcome! Avoiding the trap of age limits in health research. J Patient Cent Res Rev. 2016;3:173-5. doi: 10.17294/2330-0698.1442

Published quarterly by Midwest-based health system Advocate Aurora Health and indexed in PubMed Central, the Journal of Patient-Centered Research and Reviews (JPCRR) is an open access, peer-reviewed medical journal focused on disseminating scholarly works devoted to improving patient-centered care practices, health outcomes, and the patient experience. 


\title{
Seniors Welcome! Avoiding the Trap of Age Limits in Health Research
}

\author{
Arshad Jahangir, MD | Message from the Guest Editor \\ Sheikh Khalifa bin Hamad al Thani Center for Integrative Research on Cardiovascular Aging, \\ Aurora Research Institute, and Aurora Cardiovascular Services, Aurora Health Care, Milwaukee, WI
}

This issue of the Journal of Patient-Centered Research and Reviews covers a contemporary and underreported area in patient-centered research, that of cardiovascular diseases in the elderly. With the changing demographics of the U.S. population toward a larger group of olderage people and the higher prevalence of cardiovascular diseases in the elderly, ${ }^{1,2}$ it is important for health care researchers to concentrate their efforts on insights into aging-associated diseases, so as to reduce their effect on overall morbidity and mortality. It is disappointing that despite the known association of advancing age with cardiovascular disease and poor clinical outcomes, little is understood about mechanisms underlying aging-associated functional decline and factors that contribute to impaired quality of life, disability and loss of independence. ${ }^{3}$

The evidence base to optimally manage cardiovascular diseases in the older-elderly also is limited due to the exclusion from or scant representation in randomized clinical trials of subjects $\geq 75$ years of age and those residing in nursing homes or assisted care facilities. ${ }^{3-6}$ Even when the elderly have been included in trials, they were relatively healthy and had few comorbidities, meaning these subjects were not necessarily representative of the community. ${ }^{7}$ Therefore, clinical decision-making in the older-elderly is based on extrapolation of data obtained from studies enrolling younger patients with few comorbidities or minimal functional limitations, resulting in limited information about efficacy, safety and cost-effectiveness of interventions. ${ }^{8,9}$

Correspondence: Arshad Jahangir, MD, 2801 Kinnickinnic River Parkway, \#235, Milwaukee, WI, 53215, T: 414-649-3909,

Email: publishing44@aurora.org
As health care costs continue to rise, resources need to be directed more efficiently toward reducing disease burden and disability by focusing research efforts on prevention and early detection of disease. In addition, therapeutic selection needs to be

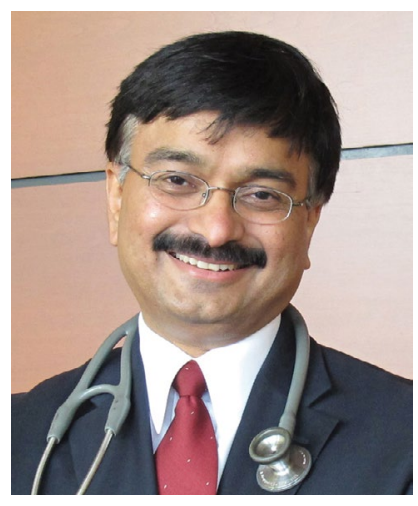
based on data that clearly demonstrate quality- and quantity-of-life benefits as well as prevention of complications and potential adverse effects that could arise in the frail elderly due to the presence of multiple comorbidities, polypharmacy and altered biology. ${ }^{10-12}$ A concerted effort by scientists, physicians and other health care providers is needed to define basic mechanisms underlying functional decline and susceptibility to disease with aging and to design better community-based studies that include a broad spectrum of elderly patients representative of those seen in clinical practice, with a focus on clinical outcomes most relevant for this population, such as functional independence and quality of life.

To forward this goal, JPCRR presents herein five articles related to the study of cardiovascular diseases in the elderly, which we hope provide a foundation on which researchers throughout the world can build improved health care models for this vulnerable and growing patient population.

In a study that used mouse embryonic cell lines, Negmadjanov et al. ${ }^{13}$ assess canonical and noncanonical intracellular pathways involved in TGF- $\beta 1$-mediated antagonism of programmed cell death of fibroblasts, the cells involved in scar formation after injury. ${ }^{14-16}$ 
Since persistence of activated fibroblasts in the heart after injury can contribute to progressive fibrosis and promotion of mechanical and electrical dysfunction thereby increasing predisposition to heart failure and $\operatorname{arrhythmias}^{17}$ - their findings are of potential clinical importance. The study's significance lies in defining the relative contribution of Smad-dependent and Erk1/2 intracellular signaling in mediation of the profibrotic effect of TGF- $\beta 1$, a cytokine that increases during inflammation, heart failure and other diseased states. Design of novel strategies may target these pathways to reduce fibrosis and resultant morbidity seen in agingassociated conditions that promote excessive and progressive tissue scarring.

Ross and Jahangir ${ }^{18}$ provide additional insight to this phenomenon, reviewing the literature on the contribution of various ion channels expressed on fibroblast cell membranes in modulating fibroblast function, including proliferation, differentiation, secretion and apoptosis, functions important for tissue repair and scar formation under physiological conditions and their respective alteration caused by age-related cardiac diseases that promote excessive fibrosis. ${ }^{16}$ Understanding the role of ion channels on cardiac fibroblasts in mediating their responses to physiological stress and pathological states may help facilitate the development of novel therapeutic strategies to limit cardiac fibrosis and its adverse effect on myocardial function.

Bhandari et al., ${ }^{19}$ in an original study using retrospective data from the National Inpatient Sample, described in-hospital outcomes of 48,872 patients hospitalized for acute mesenteric ischemia, which was more often present in patients with atrial fibrillation than those without. Patients with atrial fibrillation were more likely to be admitted emergently, were sicker and had worse outcomes, including higher in-hospital mortality. The authors also found that elderly patients with atrial fibrillation who were on anticoagulation were less likely to have serious complications from acute mesenteric ischemia, such as hemodynamic shock, small bowel resection, colectomy and need for mechanical ventilation, and had a shorter length of stay and lower hospital charges than those not on anticoagulation. This observation is important for the management of patients at risk for this serious medical condition that continues to carry high morbidity and mortality despite recent advances, ${ }^{20}$ providing supportive evidence for the recommendation of chronic anticoagulation to protect against acute mesenteric ischemia, similar to what has been validated to reduce risk of stroke in atrial fibrillation. ${ }^{21}$ Overall, the report's large sample of patients hospitalized for acute mesenteric ischemia helps fill in existing knowledge gaps regarding atrial fibrillation, since the relatively low incidence of this complication has yielded limited published information. ${ }^{22}$

In a timely review article, Dang et al. ${ }^{23}$ provide an update on stroke in atrial fibrillation, an important public health issue contributing to disability and death in elderly patients. ${ }^{1}$ The authors review pathogenesis of thromboembolism in atrial fibrillation, define predisposing clinical characteristics and risk factors for stroke and summarize select issues in its management, including the use of novel anticoagulants and nonpharmacological approaches to reducing stroke risk in older-age patients with atrial fibrillation. With the aging of the population and a projected increase in the prevalence of atrial fibrillation from about 2.3 million Americans to more than 15 million in the next 30 years, this issue cannot be ignored. ${ }^{21,22,24}$ More than one-third of patients with atrial fibrillation are greater than 80 years old, making reducing stroke risk with the use of anticoagulants without an excessive increase in serious bleeding risk a major challenge; clinical management must take into account the overall impact of age on cardiac structural and functional alterations along with comorbidities that increase stroke and bleeding risk as highlighted by the $\mathrm{CHA}_{2} \mathrm{DS}_{2}$-VASc and HAS-BLED risk scoring systems. ${ }^{21}$ The authors review challenges in stroke management among elderly patients with atrial fibrillation and highlight the need for additional studies to improve predictive modeling by incorporating clinical information on renal dysfunction, frailty, and novel biological and genetic markers to define thromboembolic and bleeding complication risk and to assess the efficacy and safety of pharmacological or nonpharmacological approaches to stroke prevention. ${ }^{3}$

Another important cardiovascular issue concerning the growing aging population is the projected rise in incidence of heart failure to 700,000 cases per year, which translates into a $46 \%$ increase in prevalence within two 
decades. ${ }^{1}$ Guzman-Gutierrez and colleagues ${ }^{25}$ provide an update on treatment options for advanced heart failure in elderly patients, who are disproportionately affected by this disease and experience high morbidity and mortality. Data on improvement in quality and quantity of life with heart transplantation and left ventricular assist device therapy and the utility of palliative care and a social support program for symptom relief is discussed. With the rapid growth of the older-elderly ( $\geq 75$ years) population, the efficacy and safety of mechanical circulatory support for advanced heart failure as destination therapy in this population needs to be better defined. Additionally, studies that improve understanding of mechanisms and define optimal management for improving survival, hospitalization, quality of life, functional capacity and cost-effectiveness in the growing number of elderly with heart failure with preserved ejection fraction are needed. ${ }^{3}$

In some ways, science is a victim of its own success. We remain grateful for the improvements in health care that have allowed more humans to live longer. Unfortunately, this progress means diseases related to cardiovascular aging threaten to reach epidemic proportions in the coming decades. Now is the time to learn as much as we can about the mechanisms affecting these conditions and to aim at developing novel therapies that improve patient outcomes.

\section{References}

1. Writing Group Members; Mozaffarian D, Benjamin EJ, Go AS, et al. Heart disease and stroke statistics - 2016 update: a report from the American Heart Association. Circulation. 2016;131:e38-360.

2. Jahangir A, Sagar S, Terzic A. Aging and cardioprotection. J Appl Physiol (1985). 2007;103:2120-8. CrossRef

3. Rich MW, Chyun DA, Skolnick AH, et al. Knowledge Gaps in Cardiovascular Care of the Older Adult Population: a scientific statement from the American Heart Association, American College of Cardiology, and American Geriatrics Society. Circulation. 2016;133:2103-22. CrossRef

4. Broekhuizen, K, Pothof A, de Craen AJ, Mooijaart SP. Characteristics of randomized controlled trials designed for elderly: a systematic review. PLoS One. 2015;10:e126709. CrossRef

5. Van Spall HG, Toren A, Kiss A, Fowler RA. Eligibility criteria of randomized controlled trials published in high-impact general medical journals: a systematic sampling review. JAMA. 2007;297:1233-40. CrossRef

6. Konrat C, Boutron I, Trinquart L, Auleley GR, Ricordeau $\mathrm{P}$, Ravaud P. Underrepresentation of elderly people in randomised controlled trials. The example of trials of 4 widely prescribed drugs. PLoS One. 2012;7:e33559. CrossRef
7. American Geriatrics Society Expert Panel on the Care of Older Adults with Multimorbidity. Guiding principles for the care of older adults with multimorbidity: an approach for clinicians. J Am Geriatr Soc. 2012;60:E1-E25. CrossRef

8. Boyd CM, Darer J, Boult C, Fried LP, Boult L, Wu AW. Clinical practice guidelines and quality of care for older patients with multiple comorbid diseases: implications for pay for performance. JAMA. 2005;294:716-24. CrossRef

9. Watts G. Why the exclusion of older people from clinical research must stop. BMJ. 2012;344:e3445. CrossRef

10. McIlvennan CK, Allen LA. Palliative care in patients with heart failure. $B M J$. 2016;353:i1010. CrossRef

11. Lauck SB, Gibson JA, Baumbusch J, et al. Transition to palliative care when transcatheter aortic valve implantation is not an option: opportunities and recommendations. Curr Opin Support Palliat Care. 2016;10:18-23. CrossRef

12. Zaslavsky O, Cochrane BB, Thompson HJ, Woods NF, Herting JR, LaCroix A. Frailty: a review of the first decade of research. Biol Res Nurs. 2013;15:422-32. CrossRef

13. Negmadjanov U, Holmuhamedov A, Emelyanova L, et al. TGF- $\beta 1$ increases resistance of NIH/3T3 fibroblasts toward apoptosis through activation of Smad2/3 and Erk1/2 pathways. J Patient Cent Res Rev. 2016;3:187-98.

14. Rizvi F, DeFranco A, Siddiqui R, et al. Chamber-specific differences in human cardiac fibroblast proliferation and responsiveness toward simvastatin. Am J Physiol Cell Physiol. 2016;311:C330-9. CrossRef

15. Rog-Zielinska EA, Norris RA, Kohl P, Markwald R. The living scar - cardiac fibroblasts and the injured heart. Trends Mol Med. 2016;22:99-114. CrossRef

16. Travers JG, Kamal FA, Robbins J, Yutzey KE, Blaxall BC. Cardiac fibrosis: the fibroblast awakens. Circ Res. 2016;118:1021-40. CrossRef

17. Turagam MK, Mirza M, Werner PH, et al. Circulating biomarkers predictive of postoperative atrial fibrillation. Cardiol Rev. 2016;24:76-87. CrossRef

18. Ross GR, Jahangir A, Functional alterations of ion channels from cardiac fibroblasts in heart diseases. J Patient Cent Res Rev. 2016;3:207-16.

19. Bhandari S, Dang G, Shahreyar M, et al. Predicting outcomes in patients with atrial fibrillation and acute mesenteric ischemia. J Patient Cent Res Rev. 2016;3:177-86.

20. Clair DG, Beach JM. Mesenteric ischemia. $N$ Engl J Med. 2016;374:959-68. CrossRef

21. January CT, Wann LS, Alpert JS, et al. 2014 AHA/ACC/HRS guideline for the management of patients with atrial fibrillation: a report of the American College of Cardiology/American Heart Association Task Force on Practice Guidelines and the Heart Rhythm Society. J Am Coll Cardiol. 2014;64:e1-76. CrossRef

22. Menke J, Lüthje L, Kastrup A, Larsen J. Thromboembolism in atrial fibrillation. Am J Cardiol. 2010;105:502-10. CrossRef

23. Dang G, Jahangir I, Sra J, Tajik AJ, Jahangir A. Atrial fibrillation and stroke in elderly patients. J Patient Cent Res Rev. 2016;3:217-29.

24. Mirza M, Strunets A, Shen WK, Jahangir A. Mechanisms of arrhythmias and conduction disorders in older adults. Clin Geriatr Med. 2012;28:555-73. CrossRef

25. Guzman-Gutierrez, G, Shi Y, Rappelt M, Jahangir A, Thohan V. Advanced heart failure treatment options among the elderly. J Patient Cent Res Rev. 2016;3:199-206.

(C) 2016 Aurora Health Care, Inc. 